BMC

Evolutionary Biology

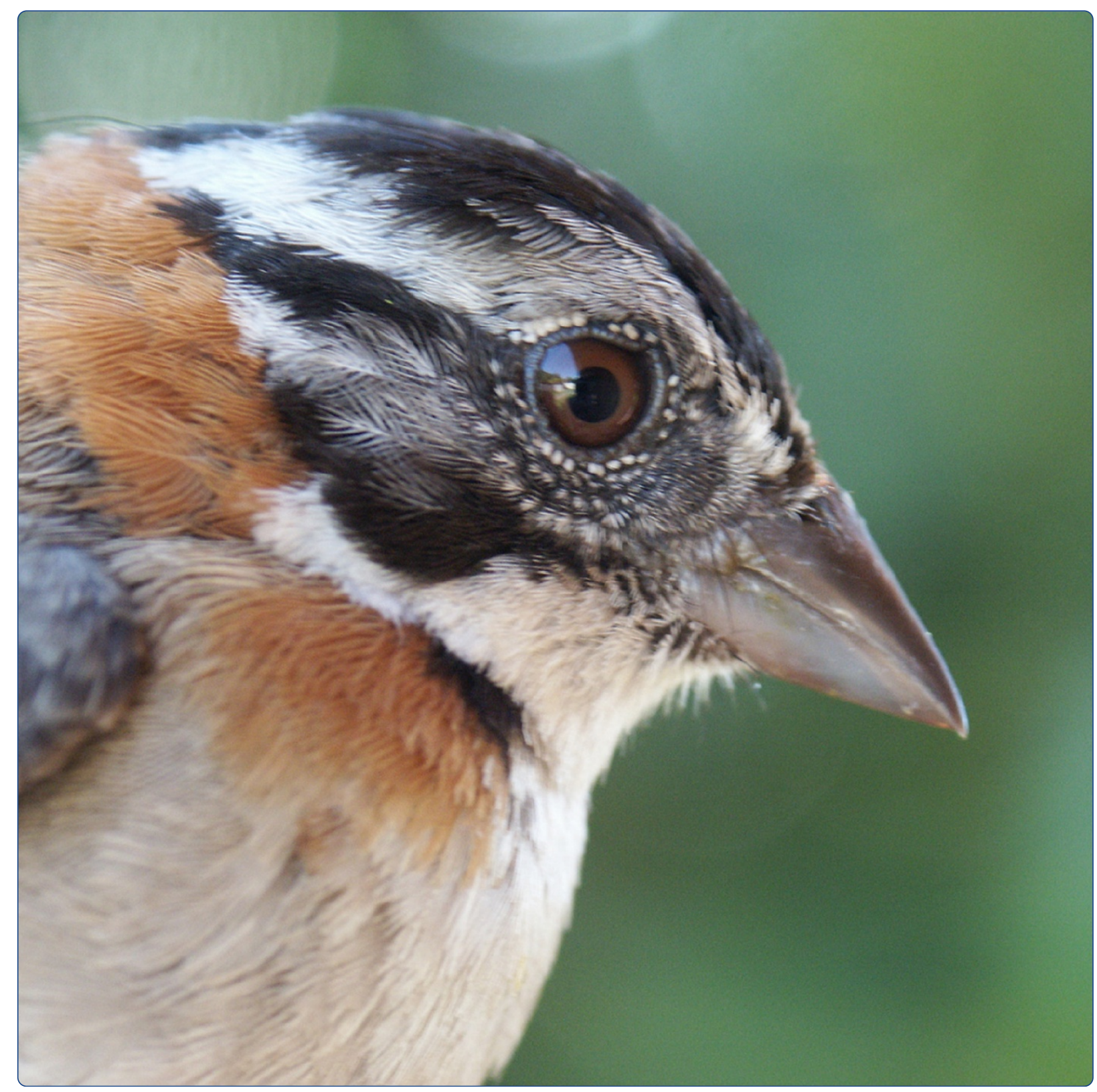

Continental phylogeography of an ecologically and morphologically diverse Neotropical songbird, Zonotrichia capensis

Lougheed et al.

() Biomed Central 


\title{
Continental phylogeography of an ecologically and morphologically diverse Neotropical songbird, Zonotrichia capensis
}

Stephen C Lougheed ${ }^{1 *}$, Leonardo Campagna ${ }^{1,2}$, José A Dávila ${ }^{3}$, Pablo L Tubaro², Darío A Lijtmaer² and Paul Handford ${ }^{4}$

\begin{abstract}
Background: The Neotropics are exceptionally diverse, containing roughly one third of all extant bird species on Earth. This remarkable species richness is thought to be a consequence of processes associated with both Andean orogenesis throughout the Tertiary, and climatic fluctuations during the Quaternary. Phylogeographic studies allow insights into how such events might have influenced evolutionary trajectories of species and ultimately contribute to a better understanding of speciation. Studies on continentally distributed species are of particular interest because different populations of such taxa may show genetic signatures of events that impacted the continentwide biota. Here we evaluate the genealogical history of one of the world's most broadly-distributed and polytypic passerines, the rufous-collared sparrow (Zonotrichia capensis).
\end{abstract}

Results: We obtained control region DNA sequences from 92 Zonotrichia capensis individuals sampled across the species' range (Central and South America). Six additional molecular markers, both nuclear and mitochondrial, were sequenced for a subset of individuals with divergent control region haplotypes. Median-joining network analysis, and Bayesian and maximum parsimony phylogenetic analyses all recovered three lineages: one spanning Middle America, the Dominican Republic, and north-western South America; one encompassing the Dominican Republic, Roraima (Venezuela) and La Paz (Bolivia) south to Tierra del Fuego, Argentina; and a third, including eastern Argentina and Brazil. Phylogenetic analyses suggest that the Middle American/north-western South American clade is sister to the remaining two. Bayesian and maximum likelihood coalescent simulations used to study lineage demographic history, diversification times, migration rates and population expansion together suggested that diversification of the three lineages occurred rapidly during the Pleistocene, with negligible gene flow, leaving genetic signatures of population expansions.

Conclusions: The Pleistocene history of the rufous-collared sparrow involved extensive range expansion from a probable Central American origin. Its remarkable morphological and behavioral diversity probably represents recent responses to local conditions overlying deeper patterns of lineage diversity, which are themselves produced by isolation and the history of colonization of South America.

Keywords: Colonization, Demographic expansion, Intraspecific divergence, DNA sequences, Pleistocene, Rufous-collared sparrow

\footnotetext{
* Correspondence: steve.lougheed@queensu.ca

'Department of Biology, Queen's University, Kingston, ON K7L 3N6, Canada

Full list of author information is available at the end of the article
}

\section{Biomed Central}

(c) 2013 Lougheed et al.; licensee BioMed Central Ltd. This is an Open Access article distributed under the terms of the Creative Commons Attribution License (http://creativecommons.org/licenses/by/2.0), which permits unrestricted use, distribution, and reproduction in any medium, provided the original work is properly cited. 


\section{Background}

Phylogeographic studies provide insight into the influence of geological and paleoclimatic events on contemporary species distributions and colonization history, and contribute to understanding the processes that might lead to new species [1]. Species with distributions on the scale of continents are particularly useful as they are often not at evolutionary equilibrium throughout their range, with distinct populations containing genetic signatures of events that have differentially impacted the continent-wide biota [2]. Phylogeographic research has focused on northern hemisphere temperate and boreal taxa, especially evaluating the influence of glaciation and postglacial dynamics; phylogeographic studies of taxa from the southern hemisphere are not as common [3].

While most of South America's continental biota has not been as deeply influenced by glaciations (e.g., [4,5]; but see [6,7]), over the last several million years, the continent has experienced marked topographic, climatic and vegetational changes, even at low and mid latitudes (e.g., [8-10]), much of this associated with orogenesis at the continent's western margins (e.g., [11-13]). The interaction of these factors has been proposed to underlie much of the hyperdiversity evident in the Neotropics (e.g., [14-17]).

The rufous-collared sparrow, Zonotrichia capensis, is an excellent species for examining the influence of a dynamic continental history on intraspecific evolutionary patterns. It is one of the most wide-ranging New World birds, distributed from Chiapas, Mexico $\left(10^{\circ} \mathrm{N}\right)$ to Tierra del Fuego, Argentina $\left(55^{\circ} \mathrm{S}\right)$. It breeds in virtually all open habitats from sea level to $>4,000$ metres above sea level, being absent only from continuous closed forest, including much of the Amazonian basin ([18]; see Figure 1A). Its four congeners (Z. albicollis, Z. atricapilla, $Z$. leucophrys, and $Z$. querula) are found only in temperate North America. This distribution has been taken by Chapman [18] to imply a Nearctic origin for the genus and, accordingly, a southward expansion of the Z. capensis ancestor from the northern temperate zone into South America. However, the historical scenario put forward by Chapman [18] is based simply on taxon concentration and does not consider the phylogenetic relationship among Zonotrichia species. Phylogenetic analyses of the genus show $Z$. capensis to be sister to all North American taxa [19-21]. This suggests that the reconstruction of the distribution of the Zonotrichia ancestor is uncertain and thus a Central or South American origin of the genus (reflecting the range of $Z$. capensis) could also be possible. Contrary to Chapman's scenario [18], such a Central or South American origin would imply an expansion and diversification towards the North, generating the clade found currently in North America, and the expansion of the $Z$. capensis lineage within Central and South America.
Recently Barker et al. [22] found Zonotrichia to be embedded within a clade with three other exclusively North American genera: Junco, Passerella and Spizella; where Junco was sister to the remaining genera. This supports a North American origin of Zonotrichia and suggests that the ancestor of $Z$. capensis subsequently expanded into South America (i.e., Chapman's 1940 scenario [18]). Regardless of the specific origin of the genus, it is likely that the ancestor of $Z$. capensis experienced many of the factors that have driven recent speciation in the Neotropics while expanding to occupy most of South America.

Zonotrichia capensis is one of the most polytypic avian species, with more than 20 described subspecies [18,23,24]. Morphological variation is accompanied by remarkable variation in vocal behaviour: low-latitude populations exhibit individual song repertories (e.g., Costa Rica [25]; Ecuador, P.H. personal observation), while others $\left(\sim 20-40^{\circ} \mathrm{S}\right)$ show individual stereotypy and geographical dialects, which correspond with natural vegetation types, but not with subspecies designations [23,26-30]. The rufous-collared sparrow also shows substantial variation in migratory habit, from lowland tropical populations that appear sedentary, through populations that undergo altitudinal migrations (e.g., altiplano populations in southern Bolivia and northern Argentina), to those that are long distance latitudinal migrants (e.g., Z. c. australis and choraules where some populations migrate more than $30^{\circ}$ in latitude). Handford [24] showed that the majority of subspecies are only weakly differentiated morphologically. The present study will help us to understand the origins and significance of such phenotypic traits in $Z$. capensis by comparing the patterns of morphological, cultural and behavioral diversity with that of historical lineage diversification.

Previous work on genetic variation in $Z$. capensis in northwestern Argentina showed differentiation between Andean and lowland populations in allozyme frequencies [31], and in mtDNA restriction fragment length polymorphisms [32]. Moreover, Cheviron and Brumfield [33] found differences in mtDNA sequences across altitudinal transects but not across latitudinal control transects in Peruvian populations of Z. capensis. Cheviron et al. [34] reported variation in transcriptomic profiles between lowland and highland environments; however these differences were not observed when birds were transplanted to a control lowland site, suggesting plastic expression patterns that allow adaptation to high altitude conditions in this species. Significant mtDNA sequence divergence between Costa Rican and Bolivian exemplars of $Z$. capensis $(2.1 \%$ in cytochrome $b)$ was noted by Zink et al. [20] and Zink and Blackwell [21]. While these data provide provocative evidence of genetic differentiation, the aforementioned studies 


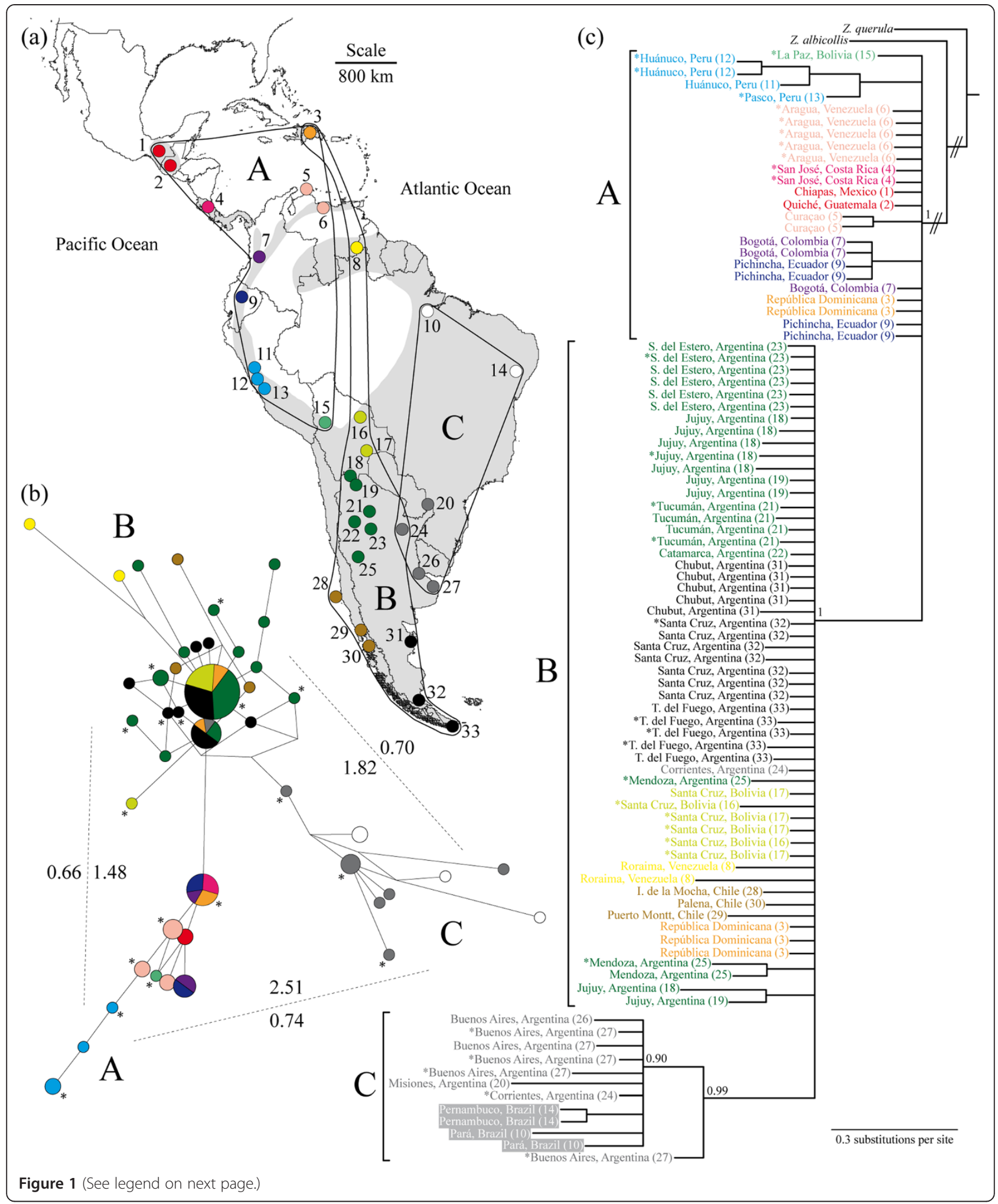




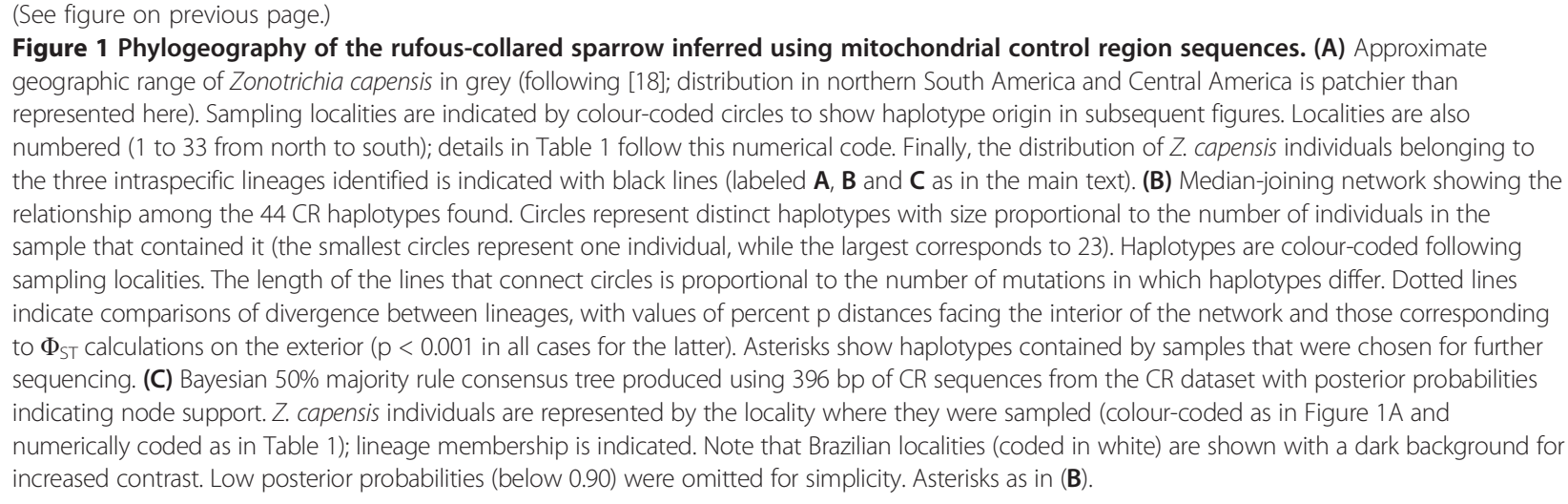

were too narrow in geographic scope to permit definite conclusions about the diversification history of the entire species.

Here we use mitochondrial and nuclear DNA sequences from individuals across the range of $Z$. capensis to examine the phylogeographic structure of this widely distributed emberizine songbird and address three questions:

1. What does the pattern of genetic diversification imply about the origin and historical demography of Zonotrichia capensis?

2. To what degree have population fragmentation and range expansion played a role in shaping genealogical patterns within the species?

3. How does phylogeographic structure relate to morphological and behavioral variation and to subspecies designations?

Our analyses revealed three main lineages within $Z$. capensis that diversified without gene flow during the Pleistocene, expanding to colonize South America from a probable Central American origin. These patterns of lineage diversity are likely the consequence of geographical isolation and the colonization of South America and do not coincide with variation reflected in subspecies designations. The remarkable morphological and behavioral diversity in the species probably represents a more recent response to local environmental conditions.

\section{Methods}

\section{Specimen information, DNA extraction and sequencing}

We obtained samples from $93 \mathrm{Z}$. capensis individuals from 33 sites across the entire breeding range (one to seven individuals per locality; Table 1, Figure 1A). We included single individuals of two congeners as outgroups: Zonotrichia querula (Harris' sparrow) and Zonotrichia albicollis (White-throated sparrow). Tissue sources include ethanol-preserved blood from live-caught and released specimens (53 individuals); preserved pectoral muscle, liver or heart tissue from specimens subsequently prepared as museum skins (23 individuals), and toe pad tissue from museum skins from critical sites (16 individuals, Table 1).

A portion of the mitochondrial control region (CR) was amplified from all individuals. We chose this locus for initial surveys because it has proved useful in similar studies of other birds [35]. We amplified and sequenced six additional markers from a subset of 32 individuals with representative divergent CR haplotypes (using fresh tissue) to help resolve phylogenetic structure. These sequences included three mitochondrial regions, cytochrome $c$ oxidase subunit I (COI), $16 \mathrm{~S}$ rDNA (16 S) and NADH dehydrogenase subunit 2 (ND2); two Zlinked markers, chromodomain-helicase-DNA binding protein (CHD1Z) and maternal embryonic leucine zipper kinase (MELK); and one autosomal intron, intron 5 of the $\beta$-fibrinogen gene (Fib5).

Genomic DNA from fresh tissue was extracted using either a standard phenol chloroform protocol [36] or the DNeasy Tissue Kit (Qiagen, Mississauga, Canada), following the manufacturer's instructions. DNA from toe pads was extracted using the latter method. For degraded DNA obtained from museum skins, we amplified a segment of the CR in small overlapping fragments generally shorter than $200 \mathrm{bp}$, using a series of primer pairs of our own design (see Additional file 1). For DNA from fresh tissue, an approximately 760 bp segment of the CR was amplified using primers ZnGluF3 and LCA1REV271 (Additional file 1). PCR cocktails were prepared in a final volume of $25 \mu \mathrm{L} \mathrm{KCl} \mathrm{PCR} \mathrm{buffer} \mathrm{(Fermentas,}$ Burlington, Canada) with the following composition: $10-20 \mathrm{ng}$ of genomic DNA, $2.5 \mathrm{mM} \mathrm{MgCl} 2,0.5 \mu \mathrm{M}$ of each primer, $0.5 \mathrm{mM}$ of dNTPs, $1 \mathrm{U}$ of Taq DNA polymerase (Fermentas). Negative controls were included for all PCRs. The thermocycling profiles were as follows: initial denaturation at $94^{\circ} \mathrm{C}$ for 2 min; 35 cycles with $30 \mathrm{~s}$ at $94^{\circ} \mathrm{C}, 20 \mathrm{~s}$ at designated annealing temperatures 
Table 1 Details of the Zonotrichia capensis samples used in this study

\begin{tabular}{|c|c|c|c|c|c|c|c|c|c|c|}
\hline Locality (Locality code) $^{a}$ & Lat./Long. & Sample type ${ }^{\mathbf{b}}$ & Sample ID ${ }^{c}$ & CR & $\mathrm{COI}$ & ND2 & $16 s$ & CHD1Z & MELK & Fib5 \\
\hline NW San Cristóbal, Chiapas, Mexico (1) & $16^{\circ} 45^{\prime} \mathrm{N}, 92^{\circ} 40^{\prime} \mathrm{W}$ & SS & AMNH 766634 & KC693420 & - & - & - & - & - & - \\
\hline Chichicastenango, Quiché, Guatemala (2) & $14^{\circ} 56^{\prime} \mathrm{N}, 91^{\circ} 07^{\prime} \mathrm{W}$ & SS & AMNH 397960 & KC693421 & - & - & - & - & - & - \\
\hline \multirow[t]{5}{*}{ República Dominicana (3) } & $19^{\circ} 20^{\prime} \mathrm{N}, 71^{\circ} 43^{\prime} \mathrm{W}$ & BS & RD-ZCA & KC693437 & - & - & - & - & - & - \\
\hline & & & RD-ZCA-2 & KC693436 & - & - & - & - & - & - \\
\hline & & & RD-ZCA-3 & KC693439 & - & - & - & - & - & - \\
\hline & & & RD-ZCA-4 & KC693438 & - & - & - & - & - & - \\
\hline & & & RD-ZCA-5 & KC693440 & - & - & - & - & - & - \\
\hline \multirow[t]{2}{*}{ La Georgina, San José, Costa Rica (4) } & $9^{\circ} 34^{\prime} \mathrm{N}, 83^{\circ} 44^{\prime} \mathrm{W}$ & MLHS & LSUMZ B16204 & KC693418 & KC693338 & KC693306 & KC693272 & KC693466 & KC693207 & KC693240 \\
\hline & & & LSUMZ B16236 & KC693419 & KC693339 & KC693307 & KC693273 & KC693467 & KC693208 & KC693241 \\
\hline \multirow[t]{2}{*}{ Curaçao (5) } & $12^{\circ} 10^{\prime} \mathrm{N}, 69^{\circ} 00^{\prime} \mathrm{W}$ & SS & AMNH 174800 & KC693428 & - & - & - & - & - & - \\
\hline & & & AMNH 174801 & KC693429 & - & - & - & - & - & - \\
\hline \multirow[t]{5}{*}{ El Junquito-Colonia Tovar, Aragua, Venezuela (6) } & $10^{\circ} 25^{\prime} \mathrm{N}, 67^{\circ} 13^{\prime} \mathrm{W}$ & MLHS & GFB3125 & KC693414 & KC693346 & KC693314 & KC693280 & KC693474 & KC693215 & - \\
\hline & & & GFB3126 & KC693415 & KC693347 & KC693315 & KC693281 & KC693475 & KC693216 & KC693248 \\
\hline & & & GFB3129 & KC693413 & KC693348 & KC693316 & KC693282 & KC693476 & KC693217 & KC693249 \\
\hline & & & GFB3142 & KC693417 & KC693349 & KC693317 & KC693283 & KC693477 & KC693218 & KC693250 \\
\hline & & & GFB3162 & KC693416 & KC693350 & KC693318 & KC693284 & KC693478 & KC693219 & - \\
\hline \multirow[t]{3}{*}{ Laguna de La Herrera, Sabana de Bogotá, Colombia (7) } & $4040^{\prime} \mathrm{N}, 74016^{\prime} \mathrm{W}$ & SS & AMNH 803019 & KC693430 & - & - & - & - & - & - \\
\hline & & & AMNH 803020 & KC693431 & - & - & - & - & - & - \\
\hline & & & AMNH 803021 & KC693432 & - & - & - & - & - & - \\
\hline \multirow[t]{2}{*}{ Summit Mt. Roraima, Roraima, Venezuela (8) } & $5^{\circ} 14^{\prime} \mathrm{N}, 60^{\circ} 47^{\prime} \mathrm{W}$ & SS & AMNH 237128 & KC693427 & - & - & - & - & - & - \\
\hline & & & AMNH 237131 & KC693426 & - & - & - & - & - & - \\
\hline \multirow[t]{4}{*}{ Quito, Pichincha, Ecuador (9) } & $0^{\circ} 13^{\prime} \mathrm{S}, 78^{\circ} 30^{\prime} \mathrm{W}$ & MLHS & PH-QUITO-2 & KC693444 & - & - & - & - & - & - \\
\hline & & & PH-QUITO-4 & KC693441 & - & - & - & - & - & - \\
\hline & & & PH-QUITO-6 & KC693443 & - & - & - & - & - & - \\
\hline & & & PH-QUITO-7 & KC693442 & - & - & - & - & - & - \\
\hline \multirow[t]{2}{*}{ Rio Tocantins- Baião, Pará, Brazil (10) } & $2^{\circ} 50^{\prime} \mathrm{S}, 49^{\circ} 36^{\prime} \mathrm{W}$ & SS & AMNH 431444 & KC693424 & - & - & - & - & - & - \\
\hline & & & AMNH 431447 & KC693425 & - & - & - & - & - & - \\
\hline Huánuco-La Unión Rd., Huánuco, Perú (11) & $9^{\circ} 53^{\prime} \mathrm{S}, 76^{\circ} 32^{\prime} \mathrm{W}$ & MLHS & LSUMZ B3603 & KC693412 & - & - & - & - & - & - \\
\hline \multirow[t]{2}{*}{ Cushi, Huánuco, Perú (12) } & $9^{\circ} 55^{\prime} \mathrm{S}, 75^{\circ} 45^{\prime} \mathrm{W}$ & MLHS & LSUMZ B8084 & KC693409 & KC693344 & KC693312 & KC693278 & KC693472 & KC693213 & KC693246 \\
\hline & & & LSUMZ B8131 & KC693410 & KC693345 & KC693313 & KC693279 & KC693473 & KC693214 & KC693247 \\
\hline Oxapampa, Pasco, Perú (13) & $10^{\circ} 34^{\prime} \mathrm{S}, 75^{\circ} 24^{\prime} \mathrm{W}$ & MLHS & LSUMZ B1875 & KC693411 & KC693342 & KC693310 & KC693276 & KC693470 & KC693211 & KC693244 \\
\hline
\end{tabular}


Table 1 Details of the Zonotrichia capensis samples used in this study (Continued)

\begin{tabular}{|c|c|c|c|c|c|c|c|c|c|c|}
\hline \multirow[t]{2}{*}{ Garanhuns, Pernambuco, Brazil (14) } & $8^{\circ} 54^{\prime} \mathrm{S}, 36^{\circ} 29^{\prime} \mathrm{W}$ & SS & AMNH 245037 & KC693422 & - & - & - & - & - & - \\
\hline & & & AMNH 245038 & KC693423 & - & - & - & - & - & - \\
\hline Chuspipita, La Paz, Bolivia (15) & $16^{\circ} 18^{\prime} S, 67^{\circ} 47^{\prime} W$ & MLHS & LSUMZ B1277 & KC693408 & KC693335 & KC693303 & KC693269 & KC693463 & KC693204 & KC693237 \\
\hline \multirow[t]{2}{*}{ Catarata Arco Iris, Santa Cruz, Bolivia (16) } & $13^{\circ} 55^{\prime} S, 60^{\circ} 45^{\prime} W$ & MLHS & LSUMZ B14823 & KC693406 & KC693336 & KC693304 & KC693270 & KC693464 & KC693205 & KC693238 \\
\hline & & & LSUMZ B14829 & KC693403 & KC693337 & KC693305 & KC693271 & KC693465 & KC693206 & KC693239 \\
\hline \multirow[t]{4}{*}{ Charagua, Santa Cruz, Bolivia (17) } & $19^{\circ} 48^{\prime} \mathrm{S}, 61^{\circ} 50^{\prime} \mathrm{W}$ & MLHS & LSUMZ B18743 & KC693404 & KC693340 & KC693308 & KC693274 & KC693468 & KC693209 & KC693242 \\
\hline & & & LSUMZ B19108 & KC693407 & KC693343 & KC693311 & KC693277 & KC693471 & KC693212 & KC693245 \\
\hline & & & LSUMZ B18745 & KC693405 & KC693341 & KC693309 & KC693275 & KC693469 & KC693210 & KC693243 \\
\hline & & & LSUMZ B18751 & KC693402 & - & - & - & - & - & - \\
\hline \multirow[t]{6}{*}{ Yavi, Jujuy, Argentina (18) } & $22^{\circ} 8^{\prime} S, 65^{\circ} 28^{\prime} W$ & BS & SCL055 & KC693359 & - & - & - & - & - & - \\
\hline & & & SCL056 & KC693360 & - & - & - & - & - & - \\
\hline & & & SCL060 & KC693361 & - & - & - & - & - & - \\
\hline & & & SCL062 & KC693362 & - & - & - & - & - & - \\
\hline & & & SCL063 & KC693363 & KC693322 & KC693288 & KC693254 & KC693448 & KC693189 & KC693223 \\
\hline & & & SCL066 & KC693364 & - & - & - & - & - & - \\
\hline \multirow[t]{3}{*}{ Tres Cruces, Jujuy, Argentina (19) } & $22^{\circ} 55^{\prime} \mathrm{S}, 65^{\circ} 35^{\prime} \mathrm{W}$ & BS & SCL071 & KC693365 & - & - & - & - & - & - \\
\hline & & & SCL072 & KC693366 & - & - & - & - & - & - \\
\hline & & & SCL074 & KC693367 & - & - & - & - & - & - \\
\hline Iguazú, Misiones, Argentina (20) & $25^{\circ} 34^{\prime} \mathrm{S}, 54^{\circ} 34^{\prime} \mathrm{W}$ & BS & SCL505 & KC693396 & - & - & - & - & - & - \\
\hline \multirow[t]{4}{*}{ Tafí del Valle, Tucumán, Argentina (21) } & $26^{\circ} 52^{\prime} S, 65^{\circ} 41^{\prime} W$ & BS & SCL084 & KC693368 & - & KC693289 & KC693255 & KC693449 & KC693190 & KC693224 \\
\hline & & & SCL085 & KC693369 & - & - & - & - & - & - \\
\hline & & & SCL086 & KC693370 & - & - & - & - & - & - \\
\hline & & & SCL088 & KC693371 & KC693323 & KC693290 & KC693256 & KC693450 & KC693191 & KC693225 \\
\hline Rd. 4230 k. SE of El Peñon, Catamarca, Argentina (22) & $26^{\circ} 4^{\prime} S, 67^{\circ} 11^{\prime} \mathrm{W}$ & MLHS & SCL009 & KC693372 & - & - & - & - & - & - \\
\hline \multirow[t]{6}{*}{ Quimilí, Santiago del Estero, Argentina (23) } & $27^{\circ} 38^{\prime} S, 62^{\circ} 25^{\prime} W$ & BS & SCL037 & KC693353 & - & - & - & - & - & - \\
\hline & & & SCL038 & KC693354 & KC693321 & KC693287 & KC693253 & KC693447 & KC693188 & KC693222 \\
\hline & & & SCL044 & KC693355 & - & - & - & - & - & - \\
\hline & & & SCL048 & KC693356 & - & - & - & - & - & - \\
\hline & & & SCL051 & KC693357 & - & - & - & - & - & - \\
\hline & & & SCL052 & KC693358 & - & - & - & - & - & - \\
\hline \multirow[t]{2}{*}{ Reserva Natural del Iberá, Corrientes, Argentina (24) } & $28^{\circ} 06^{\prime} S, 57^{\circ} 06^{\prime} W$ & BS & SCL507 & KC693397 & KC693334 & KC693302 & KC693268 & KC693462 & KC693203 & KC693236 \\
\hline & & & SCL508 & KC693398 & - & - & - & - & - & - \\
\hline
\end{tabular}


Table 1 Details of the Zonotrichia capensis samples used in this study (Continued)

\begin{tabular}{|c|c|c|c|c|c|c|c|c|c|c|}
\hline \multirow[t]{3}{*}{ Mendoza, Mendoza, Argentina (25) } & $32^{\circ} 53^{\prime} \mathrm{S}, 68^{\circ} 49^{\prime} \mathrm{W}$ & BS & SCL502 & KC693399 & KC693332 & KC693300 & KC693266 & KC693460 & KC693201 & - \\
\hline & & & SCL503 & KC693400 & KC693333 & KC693301 & KC693267 & KC693461 & KC693202 & KC693235 \\
\hline & & & SCL504 & KC693401 & - & - & - & - & - & - \\
\hline La Reja, Buenos Aires, Argentina (26) & $34^{\circ} 40 \mathrm{~S}^{\prime}, 58^{\circ} 50^{\prime} \mathrm{W}$ & BS & SCL010 & KC693390 & - & - & - & - & - & - \\
\hline \multirow[t]{5}{*}{ Magdalena, Buenos Aires, Argentina (27) } & $35^{\circ} 04^{\prime} \mathrm{S}, 57^{\circ} 32^{\prime} \mathrm{W}$ & BS & SCL110 & KC693391 & KC693328 & KC693296 & KC693262 & KC693456 & KC693197 & KC693231 \\
\hline & & & SCL111 & KC693392 & - & - & - & - & - & - \\
\hline & & & SCL112 & KC693393 & KC693329 & KC693297 & KC693263 & KC693457 & KC693198 & KC693232 \\
\hline & & & SCL113 & KC693394 & KC693330 & KC693298 & KC693264 & KC693458 & KC693199 & KC693233 \\
\hline & & & SCL115 & KC693395 & KC693331 & KC693299 & KC693265 & KC693459 & KC693200 & KC693234 \\
\hline Isla de Mocha, Arauco, Chile (28) & $38^{\circ} 23^{\prime}$ S, $73052^{\prime} \mathrm{W}$ & SS & AMNH 387432 & KC693433 & - & - & - & - & - & - \\
\hline Puerto Montt, Llanquihue, Chile (29) & $41^{\circ} 28^{\prime} \mathrm{S}, 72^{\circ} 56^{\prime} \mathrm{W}$ & SS & AMNH 182548 & KC693435 & - & - & - & - & - & - \\
\hline Golfo de Ancud, Palena, Chile (30) & $43^{\circ} 37^{\prime} \mathrm{S}, 71^{\circ} 48^{\prime} \mathrm{W}$ & SS & AMNH 182547 & KC693434 & - & - & - & - & - & - \\
\hline \multirow[t]{5}{*}{ Trelew, Chubut, Argentina (31) } & $43^{\circ} 15^{\prime} \mathrm{S}, 65^{\circ} 18^{\prime} \mathrm{W}$ & BS & SCL089 & KC693373 & - & - & - & - & - & - \\
\hline & & & SCL090 & KC693374 & - & - & - & - & - & - \\
\hline & & & SCL091 & KC693375 & - & - & - & - & - & - \\
\hline & & & SCL092 & KC693376 & - & - & - & - & - & - \\
\hline & & & SCL093 & KC693377 & - & - & - & - & - & - \\
\hline \multirow[t]{7}{*}{ Güer Aike, Santa Cruz, Argentina (32) } & $51^{\circ} 39^{\prime} \mathrm{S}, 69^{\circ} 35^{\prime} \mathrm{W}$ & BS & SCL096 & KC693378 & KC693324 & KC693291 & KC693257 & KC693451 & KC693192 & KC693226 \\
\hline & & & SCL097 & KC693379 & - & - & - & - & - & - \\
\hline & & & SCL098 & KC693380 & - & - & - & - & - & - \\
\hline & & & SCL099 & KC693381 & - & - & - & - & - & - \\
\hline & & & SCL100 & KC693382 & - & - & - & - & - & - \\
\hline & & & SCL101 & KC693383 & - & - & - & - & - & - \\
\hline & & & SCL102 & KC693384 & - & - & - & - & - & - \\
\hline \multirow[t]{6}{*}{ Ushuaia, Tierra del Fuego, Argentina (33) } & $54^{\circ} 48^{\prime} \mathrm{S}, 68^{\circ} 18^{\prime} \mathrm{W}$ & BS & SCL103 & KC693385 & - & - & - & - & - & - \\
\hline & & & SCL104 & KC693386 & KC693325 & KC693292 & KC693258 & KC693452 & KC693193 & KC693227 \\
\hline & & & SCL105 & - & - & KC693293 & KC693259 & KC693453 & KC693194 & KC693228 \\
\hline & & & SCL106 & KC693387 & KC693326 & KC693294 & KC693260 & KC693454 & KC693195 & KC693229 \\
\hline & & & SCL107 & KC693388 & KC693327 & KC693295 & KC693261 & KC693455 & KC693196 & KC693230 \\
\hline & & & SCL108 & KC693389 & - & - & - & - & - & - \\
\hline
\end{tabular}


for each primer pair (Additional file 1), $30 \mathrm{~s}$ at $72^{\circ} \mathrm{C}$; final extension at $72^{\circ} \mathrm{C}$ for $5 \mathrm{~min}$. ND2, $16 \mathrm{~S}$ and MELK were amplified following PCR conditions outlined for $\mathrm{CR}$, with the annealing temperatures and $\mathrm{MgCl}_{2}$ concentrations specified in the Additional file 1. COI amplification was conducted following Kerr et al. [37], while PCRs for CHD1Z and Fib5 followed Campagna et al. [38]. The small CR fragments amplified from toe pad DNA were electrophoresed in $0.5 \%$ agarose gels, and then excised and purified by the "freeze-squeeze" method [39]. The remaining PCR products were visualized on a $2 \%$ agarose gel using ethidium bromide and purified with the QIAquick PCR purification Kit (Qiagen). Most PCR products were sequenced bidirectionally (see Additional file 1 for primers) at the London Regional Genomics Centre (London, Canada). All sequences were deposited in Genbank; see Table 1.

We thus created two datasets: one of 92 ingroup plus 2 outgroup individuals with $396 \mathrm{bp}$ of exclusively CR DNA sequences (hereafter, the CR dataset), and another of 32 ingroup plus 2 outgroup individuals with $\approx 4200 \mathrm{bp}$ of seven molecular markers (hereafter, the multilocus dataset). Note that 92 of 93 individuals are represented in the CR dataset (see Table 1 for details).

\section{Genetic variability and phylogenetic analyses}

Sequences were aligned using BIOEDIT v7.0.9.0 [40], and those coding for proteins were visually inspected to confirm lack of indels and translated into amino acids to verify absence of stop codons. The phylogeographic structure within $Z$. capensis was initially assessed by constructing a median-joining network using the $C R$ dataset and NETWORK v4.6.1.0 (Fluxus Technology, Lt.). Differentiation between lineages identified by the network analysis was measured using $\Phi_{\mathrm{ST}}$ values calculated with ARLEQUIN v3.5.1.2 [41] and average $\mathrm{p}$ distances using MEGA v5 [42]. For the former, significance was tested through 1000 random permutations. We also performed a Bayesian phylogenetic analysis using MRBAYES v3.1.2 $[43,44]$, with the model of nucleotide evolution selected using JMODELTEST v0.1.1 [45]. The model that best fit the CR dataset according to the Akaike information criterion was the $\operatorname{TrN}$ [46] with a proportion of invariable sites $(+\mathrm{I})$. The Bayesian analyses included two simultaneous runs of seven million generations using four incrementally heated Markov chains and default priors for all parameters. The analysis was run until the standard deviation of split frequencies was $<0.01$, indicating convergence. We sampled trees every 100 generations, and after discarding the first $25 \%$ as burn-in, a $50 \%$ majority rule consensus was obtained from the combined posterior tree distribution of both runs. The potential scale reduction factor [47] was close to one for all parameters, implying that we had adequately sampled the posterior distributions. Finally, we used the 'cumulative' and 'compare' functions implemented in the software AWTY [48] to confirm that runs had reached stationarity.

We also conducted Bayesian phylogenetic analyses (as above) with the multilocus dataset using different partitioning strategies. We created trees using all seven loci, using mtDNA data alone $(\mathrm{CR}+\mathrm{COI}+16 \mathrm{~S}+$ ND2), using exclusively nuDNA (CHD1Z + MELK + Fib5), and using the DNA sequence data for each marker separately. For the seven-locus, concatenated dataset, we used two different strategies: 1 . Specifying separate partitions for each gene and allowing them to vary independently according to the model of evolution selected by JMODELTEST. 2. Using a two-partition scheme, one for mitochondrial and one for nuclear loci, again each with separate models of evolution. Partitions were unlinked, estimating parameters separately while producing a posterior tree distribution from which a $50 \%$ majority rule consensus was obtained. To explore how different phylogenetic approaches might impact tree topology, we also performed Maximum Parsimony (MP) analyses using TNT v1.1 [49]. Heuristic searches consisted of 1000 random addition sequences with the TBR branch-swapping algorithm (retaining 100 trees per replication). A strict consensus was obtained from all resulting equally parsimonious trees. We assessed node robustness by performing 1000 standard bootstrap pseudoreplicates [50], each consisting of 100 random addition sequences followed by TBR (saving ten trees per pseudoreplicate).

\section{Estimations of diversification times}

We estimated node ages using time to most recent common ancestor (TMRCA) with the Bayesian software BEAUti/BEAST v1.6.1 [51]. We calculated TMRCAs in absolute time using ND2 data with an approximate substitution rate consistent with the widely used clock calibration of $\approx 2 \%$ divergence per million years [52,53] (estimated for cytochrome $b$ in birds). In a study on $\mathrm{Ha}$ waiian Honeycreepers, Lerner et. al. [54] estimated substitution rates for various genes, including cytochrome $b$ and ND2, finding an average mitochondrial divergence rate of $1.8 \%$ per million years. Cytochrome $b$ was found to diverge approximately $2.8 \%$ per million years, while estimations for ND2 were nearly double: $5.8 \%$ divergence per million years. Given that divergence rates could also differ between ND2 and cytochrome $b$ in $Z$. capensis, as well as varying among lineages [55], we used a range of divergence values $(1,2$, and $5 \%$ per million years) to analyze the sensitivity of time estimates to variations in clock calibrations. Analyses were run for 100 million generations using the nucleotide substitution models selected with JMODELTEST (GTR + I + G [56]). 
We used a relaxed uncorrelated lognormal clock and carried out calculations twice, once assuming constant population size and again using exponential growth. Because similar TMRCA estimates were obtained regardless of prior specified we only report the former. TRACER v1.5 [57] was used to assess convergence in parameter estimates by verifying that trends were not observed in traces of parameter values and that effective sample sizes exceeded 200 .

\section{Population expansion tests and estimations of migration}

We combined mitochondrial and nuclear data to explore the demographic history of $Z$. capensis. Mitochondrial data were derived either from the $92 \mathrm{CR}$ sequences (396 bp) in the CR dataset or from the four mitochondrial loci from the 32 individuals in the multilocus dataset. In the latter case the four loci were concatenated (totaling $\approx 2700 \mathrm{bp}$ ) as they are physically linked in the mitochondrial genome. We inferred nuclear haplotypes for each locus (CHD1Z, MELK or Fib5) with DNASP v5.10 [58], using the data in subsequent analyses only if all sites had assignment probabilities $\geq 0.95$. The three nuclear loci tested negative for recombination $(\mathrm{p}>0.05)$ using the Phi test [59] implemented in SPLITSTREE v4 [60].

We tested for population demographic expansions or contractions by performing Fu's Fs test [61] using ARLEQUIN and by calculating the exponential growth parameter $g$ with LAMARC v2.1.8 [62]. Both Fu's Fs test and the population growth parameter $g$ were calculated independently for lineages A, B and C. Fu's Fs test was conducted separately for the CR dataset, the combined mitochondrial data, and for inferred haplotypes from each of the CHD1Z, MELK and Fib5 datasets. Significance was assessed using 1000 simulated replicates and departures from neutrality were interpreted as consistent with population growth. The exponential population growth parameter $g$ was calculated twice by placing either the CR dataset or the combined mitochondrial data and the inferred haplotypes from the three nuclear loci in four independent partitions. We ran LAMARC in maximum likelihood mode with the Felsenstein 84 [63] and GTR mutation models for nuclear and mitochondrial loci, respectively. Two simultaneous searches were conducted differing by $10 \%$ in the relative amount of heating incorporated. Each search consisted of two replicates of 20 initial and 5 final chains, saving 2000 and 10000 genealogies respectively in intervals of 20 generations.

Finally, we estimated migration since lineages A, B and C split using the isolation with migration model implemented in the program IMa2 [64]. We used a three-population model; the relationship between lineages followed the topology shown in Figure 2. The program was run using the CR dataset and inferred haplotypes from the three nuclear loci and applying the HKY model [65] for each locus.

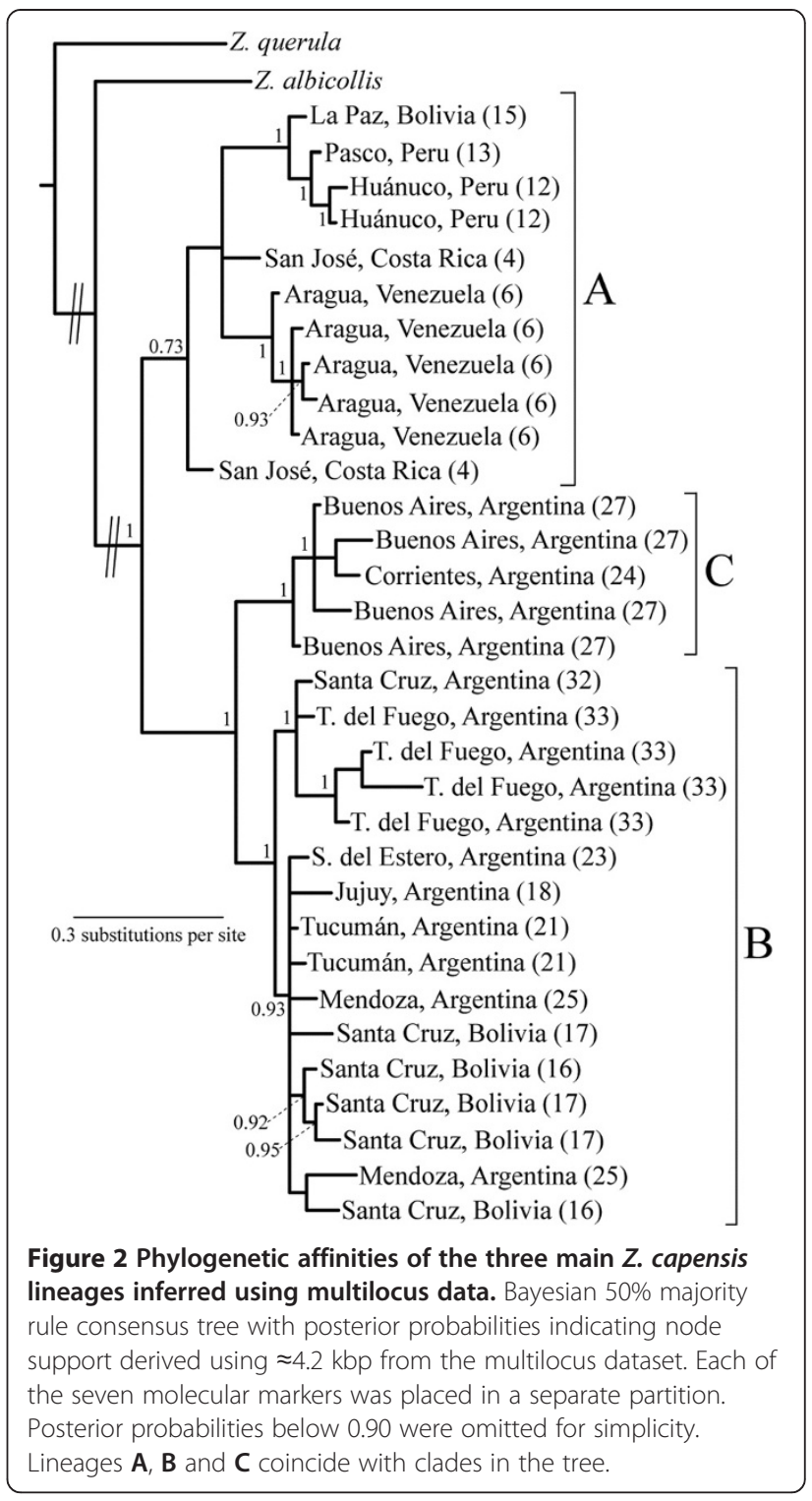

We also estimated effective population sizes and splitting times, and simplified the model by estimating one migration rate parameter per population pair. Runs in M mode showed adequate mixing with 100 chains, the geometric heating model, and a burn-in period of 250 000 generations. IMa2 was run four times with different random seeds until at least $\approx 190000$ genealogies were saved. Joint-posterior density estimations of model parameters were obtained in $\mathrm{L}$ mode.

\section{Results}

\section{Phylogeographic structure}

The 92 individuals in the $\mathrm{CR}$ dataset contained 44 distinct haplotypes, differing at 1-13 sites ( $\mathrm{p}$ distances from 0.25 to $3.28 \%$ ). Average sequence divergence ( $\mathrm{p}$ distances) 
between $Z$. capensis haplotypes and those of the two outgroups, $Z$. albicollis and Z. querula, was $6.61 \pm 0.48 \%$ and $6.94 \pm 0.45 \%$, respectively. The median-joining network analysis (Figure 1B) identified three lineages (hereafter referred to as A, B and C) comprising haplotypes separated by at least two mutational steps. Pairwise $\mathrm{p}$ distance and $\Phi_{\text {ST }}$ between these three groups ranged from 1.48 to $2.51 \%$ and 0.66 to 0.74 , respectively (Figure $1 \mathrm{~B}$ ). Lineage A includes haplotypes from northwestern South America (western Bolivia, Peru, Ecuador, Colombia and northern Venezuela), the Dominican Republic and Central America, including Chiapas, Mexico. Lineage B includes haplotypes from the Dominican Republic, Roraima (Venezuela), Santa Cruz (Bolivia), northwestern and central Argentina, Corrientes (Argentina), Chile and Patagonia (Argentina). Lineage $\mathrm{C}$ includes haplotypes from northeastern Argentina and eastern Brazil. Note that two localities show admixture of two lineages: haplotypes from A and B were found in the Dominican Republic (site 3, coded in orange in Figure 1A) and haplotypes from $B$ and $C$ were found in Corrientes, Argentina (site 24, coded in grey).

Figure 1C shows the Bayesian phylogeny from the CR dataset, where all $Z$. capensis individuals comprise a well-supported clade relative to congeneric outgroup taxa (posterior probability of 1.00). Among the three lineages identified by the network analysis, $\mathrm{C}$ was the only one that corresponded to a highly supported Bayesian clade (posterior probability of 0.99). Individuals from lineage $B$ were embedded in a polytomy with clade $C$, while individuals from lineage A formed a polytomy that also included the clade composed of all haplotypes from lineages $B$ and $C$ (Figure $1 C$ ).

To improve resolution, we carried out analyses on the multilocus dataset (individuals marked with asterisks in Figure $1 \mathrm{~B}$ and Figure $1 \mathrm{C}$ ). The Bayesian phylogeny obtained by treating our seven loci in this dataset as separate partitions (Figure 2) is well resolved and most nodes are highly supported. The three lineages indentified in the network analysis correspond to clades in this tree, although support for clade A was low (posterior probability of 0.73 ). The topology shown in Figure 2 suggests clade $\mathrm{A}$ is sister to a clade comprising clades $\mathrm{B}$ and $\mathrm{C}$. This analysis also found two subclades within clade $B$, one exclusive to Patagonia (Argentina) and the other deriving from central and northwestern Argentina and Santa Cruz (Bolivia). Alternative analyses suggest that this topology is robust, but mostly reflects information contained within the mitochondrial data (see below). Neither the Bayesian analysis that considered the mitochondrial and nuclear markers as separate partitions, nor the tree generated using maximum parsimony (Additional file 2) have strongly supported nodes contradicting those in Figure 2. Trees from the Bayesian analysis of mitochondrial data (placing each gene in a separate partition) and maximum parsimony of mitochondrial data resemble that of Figure 2, while trees derived solely from nuclear data were completely unstructured (Additional file 2; see Additional file 3 for individual gene trees), probably because of incomplete lineage sorting. Although we did not find fixed differences between lineages in the nuclear markers, there were significant haplotype frequency differences between lineage $\mathrm{A}$ and $\mathrm{B}\left(\mathrm{CHD} 1 \mathrm{Z}: \mathrm{F}_{\mathrm{ST}}=0.056\right.$; MELK: $\mathrm{F}_{\mathrm{ST}}=0.141 ;$ Fib5: $\left.\mathrm{F}_{\mathrm{ST}}=0.120\right)$.

\section{Demographic history}

Lineage B was the only one showing strong evidence of population expansion consistently across the markers surveyed. With the exception of Fib5, the remaining loci each displayed negative and statistically significant Fu's Fs values (Table 2). Moreover, the exponential growth parameter $g$ was positive and statistically significant when calculated combining the $\mathrm{CR}$ dataset with the

Table 2 Tests for demographic expansions or contractions in the three Zonotrichia capensis lineages

\begin{tabular}{|c|c|c|c|c|c|c|}
\hline & \multicolumn{2}{|l|}{ A } & \multicolumn{2}{|l|}{ B } & \multicolumn{2}{|l|}{ C } \\
\hline & $F_{s}$ & $\mathbf{p}$ & $F_{s}$ & $\mathbf{p}$ & $F_{s}$ & $\mathbf{p}$ \\
\hline CR dataset & $-3.15(25)$ & 0.046 & $-25.23(55)$ & $<0.001$ & $-3.77(12)$ & 0.006 \\
\hline Combined mitochondrial & $-1.68(11)$ & 0.150 & $-5.74(16)$ & 0.003 & $-1.48(5)$ & 0.096 \\
\hline CHD1Z & $-2.68(20)$ & 0.006 & $-1.79(28)$ & 0.036 & $-0.182(8)$ & 0.191 \\
\hline MELK & $6.61(18)$ & 0.989 & $-2.188(30)$ & 0.043 & $-0.427(6)$ & 0.180 \\
\hline Fib5 & $2.51(16)$ & 0.900 & $0.67(24)$ & 0.640 & $3.70(6)$ & 0.950 \\
\hline$g($ CR dataset + nuDNA $)$ & $165.77^{\text {ns }}(79)$ & & $669.98^{*}(137)$ & & $-30.74^{\text {ns }}(32)$ & \\
\hline$g$ (combined mitochondrial + nuDNA) & $-47.43^{\text {ns }}(65)$ & & $124.83^{\text {ns }}(98)$ & & $452.67^{\text {ns }}(25)$ & \\
\hline
\end{tabular}

Results from Fu's Fs test and calculations of the exponential growth parameter $g$ for Zonotrichia capensis lineages A, B and C (number of sequences used in each case indicated in parenthesis). Fu's Fs test was performed on mitochondrial loci from the CR dataset, the combined mitochondrial data and for inferred haplotypes from nuclear markers. Statistically significant $p$ values $(<0.05)$ are indicated in bold. For $g$, statistical significance was assessed through confidence intervals (see text for details).

*99\% confidence interval does not include 0 .

ns, not statistically significant ( $95 \%$ confidence interval includes 0$)$. 
nuclear markers, providing further evidence of population growth. The signals of demographic expansions or contractions in lineages $\mathrm{A}$ and $\mathrm{C}$ were weak, with markedly smaller Fu's Fs absolute values which were generally not statistically significant, and estimations of $g$ with 95\% confidence intervals that overlap zero (Table 2).

The events that generated the three clades most likely occurred during the Pleistocene ( $c a .0 .01$ to 2.6 million years ago). The deepest split, the node that separates clade $A$ from $B$ and $C$ in Figure 2, has a mean TMRCA of 1.45 million years assuming $2 \%$ divergence per million years (Table 3). If the limits of the $95 \%$ high posterior density intervals are considered, the former splitting time overlaps with that separating clades B and C. Moreover, if we consider alternative "slow" ( $1 \%$ divergence per million years) or "fast" ( $5 \%$ divergence per million years) molecular clock calibrations, these estimates also overlap with the split within clade B (Figure 2, Table 3). These results imply that the major cladogenic events in $Z$. capensis occurred close in time, an assertion that is also suggested by the short internode distances in Figure 2 and the extensive overlap in the posterior probability curves from splitting times estimated using IMa2 (Additional file 4). Finally, estimates of migration between pairs of lineages had 95\% high posterior density intervals that overlapped with zero (Additional file 4).

\section{Discussion}

Our analyses of sequence data from samples obtained across the range of $Z$. capensis revealed three major lineages within the species: a Middle American and northwestern South American lineage that also includes the Dominican Republic (A); a lineage encompassing the Dominican Republic, Roraima (Venezuela) and a large swath from La Paz (Bolivia) south to Tierra del Fuego, Argentina (B); and a lineage spanning the eastern portion of the species range (C: eastern Argentina and Brazil). Phylogenetic analyses suggest that clade A is sister to the other lineages. The events that gave rise to these lineages most likely occurred during the Pleistocene and were near-coincident in time. Demographic analyses implied no gene flow among lineages during their diversification; hence localities with individuals from more than one lineage in the Dominican Republic and Corrientes
(Argentina) may represent areas of repeated colonization or of secondary contact (Figure 1) and should be the focus of future studies with more in depth sampling. Finally, the most widely distributed lineage shows the strongest signal of population expansion. It is unlikely that the three $Z$. capensis lineages that span the majority of South America are panmictic and there is evidence of shallow phylogeographic structure within A and B (Figure 2), although different ways of analyzing the data do not always recover clades within these lineages (see Additional files 2 and 3). IMa2 assumes lack of population structure within lineages; thus we must be careful to not over-interpret our demographic results. While Strasburg and Rieseberg [66] found the algorithms employed by IMa2 are robust to violations of the assumption of panmixia, future studies with finer geographic resolution should seek to validate our current findings. Below we discuss these results in the context of our motivating questions.

\section{Phylogeographic patterns}

The deepest split within the species is between lineage A (Middle and northwestern South America) and all other South American samples (B and C). This pattern is consonant with previous findings in other Neotropical avian taxa (e.g., [67-69]), and has been generally interpreted as the product of vicariant events on widespread ancestral populations mediated by the uplift of the Andes Mountains. Since splits between $Z$. capensis lineages date roughly to the Pleistocene, when Andean uplift was essentially complete [12], and given that the species mostly inhabits open country, which in tropical latitudes is restricted to higher elevations $[18,70]$, this explanation seems implausible. Alternatively, Quaternary climatic processes have also deeply influenced speciation in Neotropical taxa (e.g., [17,71]), particularly through climate changes related to glacial cycles and their effects on species distributions. Thus Pleistocene glaciations may have helped isolate and shape $Z$. capensis lineages. The pattern could also reflect a history of geographical isolation and colonization of South America largely consistent with Chapman's model [18] - see below.

It is possible that the genus originated in North America with subsequent differentiation of the four northern species and a southward expansion of the $Z$. capensis

Table 3 Estimations of timing of splitting events between Zonotrichia capensis lineages

\begin{tabular}{llllll}
\hline & Mean "fast" clock (5\%) & Low 95\% HPD (2\%) & Mean (2\%) & High 95\% HPD (2\%) & Mean "slow" clock (1\%) \\
\hline ABC (32) & 0.58 & 0.70 & $\mathbf{1 . 4 5}$ & 2.38 & 2.88 \\
BC (21) & 0.34 & 0.40 & $\mathbf{0 . 8 6}$ & 1.42 & 1.71 \\
B (16) & 0.15 & 0.15 & $\mathbf{0 . 3 7}$ & 0.64 & 0.74 \\
\hline
\end{tabular}

TMRCA and 95\% confidence intervals (in units of millions of years) for three different nodes in the tree shown in Figure 2. Values were estimated using BEAST and ND2 sequences with $a \approx 2 \%$ per million year divergence rate [52] (in bold). Sample sizes are in parenthesis after each node. The mean values obtained using alternative calibrations of 1 and $5 \%$ per million years ("slow" and "fast" clocks, respectively) are also reported. 
ancestor that led to the genealogical patterns evident in the species. We note that the divergence between our two outgroup taxa $(\approx 1.8 \% \mathrm{p}$ distance in CR between $Z$. albicollis and $Z$. querula) is comparable to that among $Z$. capensis lineages, implying a similar timeframe for diversification between north-temperate Zonotrichia species and lineages within the single Neotropical species. Other studies of lower latitude taxa have shown greater neutral genetic divergence and stronger phylogeographic structure than their temperate counterparts (e.g., $[4,5,72])$.

Our results are consistent with two South American colonization hypotheses that assume a Central America origin for $Z$. capensis and range expansion facilitated by open country. One is consistent with Chapman's [18] inference: An eastward colonization along the margins of the Caribbean and Atlantic Ocean and then southwards into Brazil, together with a colonization southwards along the Andean chain towards Argentina. The second involves this same southward Andean colonization, followed by an eastward expansion into low elevation open habitats south of the southern limits of the Amazonian forest systems of the eastern Andean slopes (currently at $\approx 27^{\circ} \mathrm{S}$ ). This expansion would have continued southward into Patagonia and northeast along the "arid diagonal" of the chaco-cerrado-caatinga into eastern Argentina, Paraguay and sub-Amazonian Brazil. Additional sampling from areas that are poorly represented in or entirely absent from our study (e.g., southern Venezuela, Guyana, French Guyana, Suriname, Brazil, northern Chile and western Bolivia) will allow greater insight into how this species colonized South America.

In earlier work, Lougheed and Handford [31] and Lougheed et al. [32] speculated that the genetic differentiation uncovered in northwestern Andean Argentina represented a secondary contact of two postulated primary clades representing the major routes of colonization of South America proposed by Chapman [18]. Our results show the differentiation that they found is encompassed within lineage $B$ and perhaps a consequence of more recent distributional changes.

Finally, while we found substantial phylogeographic structure within $Z$. capensis, lineages in this species are not as divergent as those in other Neotropical species with comparable ranges (e.g., Troglodytes aedon: [73]; Cistothorus platensis: M. Robbins, University of Kansas Biodiversity Institute, personal communication). Recent mitochondrial surveys including many Neotropical bird taxa have also shown deep divergence within species with much smaller geographic ranges (e.g., see $[37,74]$ ). While future studies should clarify if these deeply diverged lineages in other taxa are reproductively isolated cryptic species, we suspect that the ecological flexibility of the rufous-collared sparrow, which is known to rapidly colonize newly-opened terrain, explains the lack of deep divergence over a wide range spanning over 70 degrees of latitude.

\section{Lack of correlation between phylogeographic structure and phenotypic variation}

Mitochondrial phylogeographic structure does not reflect the subspecific taxonomy of the rufous-collared sparrow [75], consonant with the findings of other studies in many taxa (e.g., [76-78]). Moreover, Handford [24] showed that $Z$. capensis subspecies cannot be recovered even from morphometric data. This is perhaps not surprising given that phenotypic responses to local environmental circumstances may occur rapidly regardless of historical fragmentation of populations (e.g., $[79,80])$. Furthermore, no studies have yet been published quantifying heritability in the traits that differentiate $Z$. capensis subspecies.

The three diagnosed lineages each include several subspecies (at least seven in lineage $\mathrm{A}$, eight in lineage $\mathrm{B}$, and three in lineage $C$ - see [18] for a detailed discussion on subspecies distributions). Moreover, some subspecies are represented in two lineages (e.g., Z. c. antillarum in lineages A and B; Z. c. hypoleuca in lineages B and C). However one well-supported subclade within lineage $B$ included individuals exclusively from the southernmost portion of the species range, all belonging to subspecies $Z$. c. australis (Figure 2). This suggests that glaciations in Patagonia might have played a role in isolating southern populations of rufous-collared sparrows, which subsequently expanded their range after the ice retreated, a scenario that has been documented in other southern Neotropical taxa [7].

Our findings provide no clear evidence that variation in vocal behavior in $Z$. capensis relates to major phylogeographic divisions. Habitat-related geographical vocal dialects are documented from Argentina in both lineages B and $\mathrm{C}$, with high levels of song differentiation found throughout northwestern and central Argentina, which is occupied by the single lineage $B$, and similarly differentiated songs in grassland and wooded environments in the parts of Argentina occupied by lineage C (Entre Rios, Corrientes, Buenos Aires). Habitat-related dialects extend at least into northern Patagonia, with distinctive songs in the Patagonian shrub-steppe and Andean woodlands, but we must acknowledge that vocal behaviour is poorly understood south of $\approx 40^{\circ} \mathrm{S}$ in the range occupied by highly migratory populations. Similarly, though we know that there is geographical variation in song in Brazil [81], it is too poorly known for generalizations to be made.

On the other hand, substantial individual repertoires and an evident lack of habitat-related dialects are known only from regions encompassed by lineage A (Costa Rica; Ecuador). This raises the possibility that dialects are the derived condition (and that the systems of song dialects that exist in some of the North American Zonotrichia are independently derived). In any event, 
the association between vegetation structure and vocal dialects must have developed recently and dialect distribution is not reflected in the genealogical relationships that we have reported on here. Thus, we provisionally conclude that vocal variation in rufous-collared sparrows is probably a manifestation of cultural evolution that overlies deeper intraspecific genealogical patterns.

\section{Conclusions}

These results suggest a Pleistocene history of colonization and population expansion in the rufous-collared sparrow from a probable Central American origin. Diversification occurred during the Pleistocene, a time of substantial global climate fluctuations and variation in the extent and distribution of different vegetation types. The impressive diversity in morphology, migratory habit, and vocal system of this species most probably represents recent responses to local conditions and overlies deeper patterns of lineage diversity that are products of geographical isolation and the colonization history of South America. That subspecies are not reflected in major phylogeographic divisions is not surprising in light of patterns exhibited by many other taxa, but this does not preclude the possibility that local adaptation may modulate the evolutionary trajectories of this species.

The deepest split in the species is between a Central American/tropical Andean clade and all other populations to the south and east. Phylogeographic patterns are consistent with two colonization scenarios of South America following either: a) a colonization southwards along the Andes and an eastward and then southward colonization along the margins of the Caribbean and Atlantic Ocean, or b) this same southward Andean colonization, followed by an eastward and then southward colonizations into Patagonia and towards the northeast into eastern Argentina, Paraguay and Brazil. To enhance insights into the processes that influenced the evolutionary history of this widespread passerine, future investigations should increase geographic sampling intensity in the northeastern portion of the species range and evaluate alternative scenarios through a more rigorous hypothesis-testing framework (such as Approximate Bayesian computation).

\section{Additional files}

Additional file 1: Table of all primers and PCR conditions used to amplify loci in the study.

Additional file 2: Bayesian and Maximum Parsimony trees generated using alternative partitioning strategies to analyze the multilocus dataset.

Additional file 3: Bayesian individual gene trees.

Additional file 4: Posterior density curves for splitting times, migration rates and effective population sizes estimated using IMa2.

\section{Competing interests}

The authors declare that they have no competing interests.

\section{Authors' contributions}

SCL, PLT and PH conceived the ideas; SCL, LC, JAD and DAL collected the data; SCL and LC analyzed the data and led the writing, with help from the other authors. All authors read and approved the final manuscript.

\section{Authors' information}

Collectively, we are interested in understanding the origins of biodiversity from the level of local adaptation and limiting gene flow in single landscapes, through the genetics of entire species' ranges, to understanding the causes of diversification of entire clades. Our research spans the Americas, with particular emphasis on phylogeography and phylogenetics of select anurans, squamates and birds.

\section{Acknowledgements}

We especially thank Ricardo and Susana Ojeda, Patricia Capllonch, Rubén, Daniel and Isaac Bárquez, and Catalina and Gunilla Olrog for their support during our Argentine fieldwork. We gratefully acknowledge the help and hospitality of Gabriel and Andrea Punta, Gonzalo Herrera, Hector and Marcela Cruz, Coyi Barrientos, Carlos Fermani and Nora Loekemeyer. Additional samples were kindly provided by George Barrowclough (AMNH), Elderedge Bermingham (STRI), and Donna Dittmann and Van Remsen (LSUMZ). For our fieldwork in Argentina we thank all provincial and national authorities for permission to collect and export/import samples including those from the province of Tucumán (Claudia Pérez-Miranda), Catamarca (Enrique Fra), and Jujuy (Rene Cabezas). Daria Koscinski, Hanifah Dostmohamed and Nadine Sharpe provided laboratory expertise. Funding was provided by NSERC Discovery grants to Lougheed and Handford, by CONICET, ANPCYT and IDRC, and by a National Geographic Society Research Grant to Chris Moyes. We thank two anonymous reviewers for their helpful comments on previous versions of this manuscript.

\section{Author details}

${ }^{1}$ Department of Biology, Queen's University, Kingston, ON K7L 3N6, Canada. División de Ornitología, Museo Argentino de Ciencias Naturales "Bernardino Rivadavia", Avenida Ángel Gallardo 470, Ciudad de Buenos Aires, Buenos Aires C1405DJR, Argentina. ${ }^{3}$ Instituto de Investigación en Recursos Cinegéticos, Ronda de Toledo s/n, Cuidad Real 13005, Spain. ${ }^{4}$ Department of Biology, University of Western Ontario, London, ON N6A 5B7, Canada.

Received: 28 November 2012 Accepted: 26 February 2013

Published: 1 March 2013

\section{References}

1. Hewitt GM: Speciation, hybrid zones and phylogeography - or seeing genes in space and time. Mol Ecol 2001, 10:537-549.

2. Adams SM, Lindmeier JB, Duvernell DD: Microsatellite analysis of the phylogeography, Pleistocene history and secondary contact hypotheses for the killifish, Fundulus heteroclitus. Mol Ecol 2006, 15:1109-1123.

3. Beheregaray LB: Twenty years of phylogeography: the state of the field and challenges for the Southern Hemisphere. Mol Ecol 2008, 17:3754-3774.

4. Milá B, Girman DJ, Kimura M, Smith TB: Genetic evidence for the effect of a postglacial population expansion on the phylogeography of a North American songbird. P Roy Soc B-Biol Sci 2000, 267:1033-1040.

5. Lessa EP, Cook JA, Patton JL: Genetic footprints of demographic expansion in North America, but not Amazonia, during the late Quaternary. P Natl Acad Sci USA 2003, 100:10331-10334.

6. Zemlak TS, Habit EM, Walde SJ, Battini MA, Adams ED, Ruzzante DE: Across the southern Andes on fin: glacial refugia, drainage reversals and a secondary contact zone revealed by the phylogeographical signal of Galaxias platei in Patagonia. Mol Ecol 2008, 17:5049-5061.

7. Lessa EP, D'Elía G, Pardiñas UFJ: Genetic footprints of late Quaternary climate change in the diversity of Patagonian-Fueguian rodents. Mol Ecol 2010, 19:3031-3037.

8. Bush MB, Colinvaux PA, Wiemann MC, Piperno DR, Liu K: Late Pleistocene temperature depression and vegetation change in Ecuadorian Amazonia. Quaternary Res 1990, 34:330-345. 
9. Sanaiotti TM, Martinelli LA, Victoria RL, Trumbore SE, Camargo PB: Past vegetational changes in Amazon savannas determined using carbon isotopes of soil organic matter. Biotropica 2002, 34:2-16.

10. Ledru MP, Rousseau DD, Cruz FW, Riccomini C, Karmann I, Martin L: Paleoclimate changes during the last $100,000 \mathrm{yr}$ from a record in the Brasilian Atlantic rainforest region and interhemispheric comparison. Quaternary Res 2005, 64:444-450.

11. Ramos VA: Plate tectonic setting of the Andean cordillera. Episodes 1999, 22:183-190.

12. Garzione CN, Hoke GD, Libarkin JC, Withers S, MacFadden B, Eiler J, Ghosh P, Mulch A: Rise of the Andes. Science 2008, 320:1304-1307.

13. Hoorn C, Wesselingh FP, ter Steege H, Bermudez MA, Mora A, Sevink J, Sanmartín I, Sanchez-Meseguer A, Anderson CL, Figueiredo JP, Jaramillo C, Riff D, Negri FR, Hooghiemstra H, Lundberg J, Stadler T, Särkinen T, Antonelli A: Amazonia through time: Andean uplift, climate change, landscape evolution, and biodiversity. Science 2011, 330:927-931

14. Haffer J: Alternative models of vertebrate speciation in Amazonia: an overview. Biodivers Conserv 1997, 6:451-476.

15. Roy MS, da Silva JM C, Arctander P, García-Moreno J, Fjeldså J: The speciation of South American and African birds in montane regions. In Avian Molecular Evolution and Systematics. Edited by Mindell DP. San Diego: Academic Press; 1997:325-343.

16. Hubert N, Renno J-F: Historical biogeography of South American freshwater fishes. J Biogeogr 2006, 33:1414-1436.

17. Brumfield RT: Inferring the origins of lowland Neotropical birds. Auk 2012, 129:367-376.

18. Chapman FM: The post-glacial history of Zonotrichia capensis. B Am Mus Nat Hist 1940, 77:381-438.

19. Zink RM: Patterns of genic and morphologic variation among sparrows in the genera Zonotrichia, Melospiza, Junco, and Passerella. Auk 1982, 99:632-649.

20. Zink RM, Dittmann DL, Rootes WL: Mitochondrial DNA variation and the phylogeny of Zonotrichia. Auk 1991, 108:578-584.

21. Zink RM, Blackwell RC: Patterns of allozyme, mitochondrial DNA, and morphometric variation in four sparrow genera. Auk 1996, 113:59-67.

22. Barker FK, Burns KJ, Klicka J, Lanyon SM, Lovette IJ: Going to extremes: contrasting rates of diversification in a recent radiation of new world passerine birds. Syst Biol 2013, 62:298-320.

23. Handford P: Continental patterns of morphological variation in a South American sparrow. Evolution 1983, 37:920-930.

24. Handford P: Morphological relationships among subspecies of the rufous-collared sparrow, Zonotrichia capensis. Can J Zoolog 1985, 63:2383-2388.

25. Fotheringham JR: Differences in singing behavior between rufouscollared sparrows in Costa Rica and Northwestern Argentina. Condor 1995, 97:821-826.

26. Nottebohm F: The song of the chingolo, Zonotrichia capensis, in Argentina. Condor 1969, 71:299-315.

27. Handford P: Trill rate dialects in the rufous-collared sparrow, Zonotrichia capensis. Can J Zoolog 1988, 66:2658-2670.

28. Handford P: Latin accents: song dialects of a South American sparrow. Birding 2005, 37:510-519.

29. Handford P, Lougheed SC: Variation in duration and frequency characters in the song of the rufous-collared sparrow, Zonotrichia capensis, with respect to habitat, trill dialects and body size. Condor 1991, 93:644-658.

30. Lijtmaer DA, Tubaro PL: A reversed pattern of association between song dialects and habitat in the rufous-collared sparrow. Condor 2007, 109:658-667.

31. Lougheed SC, Handford P: Vocal dialects and the structure of geographic variation in morphological and allozymic frequency characters in the rufous-collared sparrow, Zonotrichia capensis. Evolution 1992, 46:1443-1456.

32. Lougheed SC, Handford P, Baker AJ: Mitochondrial DNA hyperdiversity and vocal dialects in a subspecies transition of the rufous-collared sparrow. Condor 1993, 95:889-895.

33. Cheviron ZA, Brumfield RT: Migration-selection balance and local adaptation of mitochondrial haplotypes in rufous-collared sparrows (Zonotrichia capensis) along an elevational gradient. Evolution 2009, 63:1593-1605.

34. Cheviron ZA, Whitehead A, Brumfield RT: Transcriptomic variation and plasticity in rufous-collared sparrows (Zonotrichia capensis) along an elevational gradient. Mol Ecol 2008, 17:4556-4569.
35. Baker AJ, Marshall HD: Mitochondrial control region sequences as tools for understanding evolution. In Avian molecular evolution and systematics. Edited by Mindell DP. San Diego: Academic press; 1997:51-82.

36. Sambrook J, Fritsch EF, Maniatis T: Molecular cloning: a laboratory manual. 2nd edition. New York: Cold Spring Harbor Laboratory Press; 1989.

37. Kerr KC, Lijtmaer DA, Barreira AS, Hebert PDN, Tubaro PL: Probing evolutionary patterns in Neotropical birds through DNA barcodes. PLoS One 2009, 4:e4379.

38. Campagna L, Benites P, Lougheed SC, Lijtmaer DA, Di Giacomo AS, Eaton MD, Tubaro PL: Rapid phenotypic evolution during incipient speciation in a continental avian radiation. P Roy Soc B-Biol Sci 2011, 279:1847-1856.

39. Thuring RWJ, Sanders JPM, Borst P: A freeze-squeeze method for recovering long DNA from agarose gels. Anal Biochem 1975, 66:213-220.

40. Hall TA: BIOEDIT: a user-friendly biological sequence alignment editor and analysis program for Windows 95 / 98 / NT. Nucl Acid S 1999, 41:95-98.

41. Excoffier L, Lischer HEL: Arlequin suite ver 3.5: a new series of programs to perform population genetics analyses under Linux and Windows. Mol Ecol Resour 2010, 10:564-567.

42. Tamura K, Peterson D, Peterson N, Stecher G, Nei M, Kumar S: MEGA5: molecular evolutionary genetics analysis using maximum likelihood, evolutionary distance, and maximum parsimony methods. Mol Biol Evol 2011, 28:2731-2739.

43. Huelsenbeck JP, Ronquist F: MRBAYES: Bayesian inference of phylogenetic trees. Bioinformatics 2001, 17:754-755.

44. Ronquist F, Huelsenbeck JP: MrBayes 3: Bayesian phylogenetic inference under mixed models. Bioinformatics 2003, 19:1572-1574.

45. Posada D: jModelTest: phylogenetic model averaging. Mol Biol Evol 2008, 25:1253-1256.

46. Tamura K, Nei M: Estimation of the number of nucleotide substitutions in the control region of mitochondrial DNA in humans and chimpanzees. Mol Biol Evol 1993, 10:512-526.

47. Gelman A, Rubin DB: Inference form iterative simulation using multiple sequences. Stat Sci 1992, 7:457-472.

48. Wilgenbusch JC, Warren DL, Swofford DL: AWTY: a system for graphical exploration of MCMC convergence in Bayesian phylogenetic inference. http://ceb.csit.fsu.edu/awty.

49. Goloboff P, Farris S, Nixon K: TNT: tree analysis using New technology. Program and documentation, available from the authors, and at. http://www.zmuc.dk/public/phylogeny.

50. Felsenstein J: Confidence limits on phylogenies: an approach using the bootstrap. Evolution 1985, 39:783-791.

51. Drummond AJ, Rambaut A: BEAST: Bayesian evolutionary analysis by sampling trees. BMC Evol Biol 2007, 7:214

52. Weir JT, Schluter D: Ice sheets promote speciation in boreal birds. P Roy Soc B-Biol Sci 2004, 271:1881-1887.

53. Weir JT, Schluter D: Calibrating the avian molecular clock. Mol Ecol 2008, 17:2321-2328

54. Lerner HRL, Meyer M, James HF, Hofreiter M, Fleischer RC: Multilocus resolution of phylogeny and timescale in the extant adaptive radiation of Hawaiian honeycreepers. Curr Biol 2011, 21:1838-1844.

55. Lovette IJ: Mitochondrial dating and mixed-support for the " $2 \%$ rule" in birds. Auk 2004, 121:1-6.

56. Tavare S: Some probabilistic and statistical problems in the analysis of DNA sequences. In Some mathematical questions in biology - DNA sequence analysis. Edited by Miura RM. Providence, Rhode Island: American Mathematical Society; 1986:57-86.

57. Rambaut A, Drummond AJ: Tracer v1.4. http://beast.bio.ed.ac.uk/Tracer.

58. Librado P, Rozas J: DnaSP v5: a software for comprehensive analysis of DNA polymorphism data. Bioinformatics 2009, 25:1451-1452.

59. Bruen TC, Philippe $H$, Bryant D: A simple and robust statistical test for detecting the presence of recombination. Genetics 2006, 172:2665-2681.

60. Huson DH, Bryant D: Application of phylogenetic networks in evolutionary studies. Mol Biol Evol 2006, 23:254-267.

61. Fu YX: Statistical tests of neutrality of mutations against population growth, hitchhiking and background selection. Genetics 1997, 147:915-925.

62. Kuhner MK: LAMARC 2.0: maximum likelihood and Bayesian estimation of population parameters. Bioinformatics 2006, 22:768-770.

63. Felsenstein J: Distance methods for inferring phylogenies: a justification. Evolution 1984, 38:16-24.

64. Hey J: Isolation with migration models for more than two populations. Mol Biol Evol 2010, 27:905-920. 
65. Hasegawa M, Kishino H, Yano TA: Dating of the human-ape splitting by a molecular clock of mitochondrial DNA. J Mol Evol 1985, 22:160-174.

66. Strasburg JL, Rieseberg LH: How robust are "isolation with migration" analyses to violations of the IM model? A simulation study. Mol Biol Evol 2010, 27:297-310.

67. Cracraft J, Prum RO: Patterns and processes of diversification: speciation and historical congruence in some Neotropical birds. Evolution 1988, 42:603-620.

68. Brumfield RT, Capparella AP: Historical diversification of birds in northwestern South America: a molecular perspective on the role of vicariant events. Evolution 1996, 50:1607-1624.

69. Sedano RE, Burns KJ: Are the northern Andes a species pump for Neotropical birds? Phylogenetics and biogeography of a clade of Neotropical tanagers (Aves: Thraupini). J Biogeogr 2010, 37:325-343.

70. Bond J: Origin of the bird fauna of the West Indies. The Wilson Bulletin 1948, 60:207-229.

71. Rull V: Speciation timing and Neotropical biodiversity: the TertiaryQuaternary debate in the light of molecular phylogenetic evidence. Mol Ecol 2009, 17:2722-2729.

72. Chek AA, Austin JD, Lougheed SC: Why is there a tropical-temperate disparity in the genetic diversity and taxonomy of species? Evol Ecol Res 2003, 5:69-77.

73. Campagna L, St Clair JJH, Lougheed SC, Woods RW, Imberti S, Tubaro PL Divergence between passerine populations from the Malvinas - Falkland islands and their continental counterparts: a comparative phylogeographical study. Biol J Linn Soc 2012, 106:865-879.

74. Tavares ES, Gonçalves P, Miyaki CY, Baker AJ: DNA barcode detects high genetic structure within Neotropical bird species. PLoS One 2011, 6:e28543.

75. American Ornithologists' Union (AOU): Check-list of north American birds. 7th edition. Washington, D.C: American Ornithologists' Union; 1998.

76. Zink RM, Barrowclough GF, Atwood JL, Blackwell-Rago RC: Genetics, taxonomy and conservation of the threatened California gnatcatcher. Conser Biol 2000, 14:1394-1405

77. Scribner KT, Talbot SL, Pearce JM, Pierson BJ, Bollinger KS, Derksen DV: Phylogeography of Canada geese (Branta canadensis) in western North America. Auk 2003, 120:889-907.

78. Zink RM: The role of subspecies obscuring avian biological diversity and misleading conservation policy. P Roy Soc B-Biol Sci 2004, 271:561-564.

79. Legge JT, Roush R, DeSalle R, Vogler AP, May B: Genetic criteria for establishing evolutionarily significant units in Cryan's buckmoth. Conserv Biol 1996, 10:85-98.

80. McKay BD, Zink RM: The causes of mitochondrial DNA gene tree paraphyly in birds. Mol Phylogenet Evol 2010, 54:647-650.

81. Avelino MF, Vielliard JME: Comparative analysis of the song of the rufouscollared sparrow Zonotrichia capensis (Emberizidae) between Campinas and Botucatu, São Paulo state, Brazil. An Acad Bras Cienc 2004, 76:345-349.

doi:10.1186/1471-2148-13-58

Cite this article as: Lougheed et al: Continental phylogeography of an ecologically and morphologically diverse Neotropical songbird,

Zonotrichia capensis. BMC Evolutionary Biology 2013 13:58.

\section{Submit your next manuscript to BioMed Central and take full advantage of:}

- Convenient online submission

- Thorough peer review

- No space constraints or color figure charges

- Immediate publication on acceptance

- Inclusion in PubMed, CAS, Scopus and Google Scholar

- Research which is freely available for redistribution 